\title{
Clinical characteristics of eperisone-induced immediate-type hypersensitivity
}

\author{
Bomi Shin, ${ }^{1}$ Sun-Young Yoon, ${ }^{2 *}$ Ji-Hyang Lee, ${ }^{1}$ Ha-Kyeong Won, ${ }^{1}$ Jin An, ${ }^{1}$ Yewon Kang, ${ }^{1}$ Woo-Jung Song, ${ }^{1}$ Tae-Bum Kim, ${ }^{1}$ \\ You Sook Cho, ${ }^{1}$ Hee-Bom Moon, ${ }^{1}$ Hyouk-Soo Kwon ${ }^{1 \star}$
}

\begin{abstract}
Background: Eperisone is a commonly prescribed oral muscle relaxant, but few studies have been conducted of eperisone-induced hypersensitivity reactions.
\end{abstract}

Objective: The purpose of this study was to investigate the clinical manifestations of eperisone-induced immediate-type hypersensitivity, and to evaluate the role of an intradermal test (IDT) in eperisone-induced anaphylaxis.

Methods: This study was based on a retrospective review of medical records from 23 patients diagnosed as eperisone-induced immediate-type hypersensitivity with certain or probable causality. Intradermal tests were performed with a sterile $10 \mathrm{mg} / \mathrm{mL}$ eperisone solution.

Results: Immediate-type hypersensitivity reactions to eperisone occurred within 15 minutes in $8.7 \%$, within 30 minutes in $52.2 \%$, and within 60 minutes in $82.6 \%$ of the patients, cumulatively. All patients showed cutaneous symptoms. Gastrointestinal symptoms were the second-most frequent (65.2\%), respiratory symptoms (56.5\%) followed, and cardiovascular symptoms were the least $(39.1 \%)$. Nine $(39.1 \%)$ patients were categorized as severe anaphylaxis. The mean onset time of severe anaphylaxis was 28.89 minutes, which was significantly shorter than non-severe anaphylaxis $(p=0.011)$. Five patients among the severe anaphylaxis group were evaluated with IDT, and all showed positive results. In contrast, all of the four patients who have done IDT among the moderate anaphylaxis group showed negative results. There was a significant relationship between severe anaphylaxis and positive IDT results $(p=0.008)$.

Conclusions: Eperisone-induced immediate-type hypersensitivity is not uncommon in Korea, and the IDT could be a useful and safe diagnostic tool, especially in severe anaphylaxis.

Key words: eperisone, intradermal test, drug hypersensitivity, anaphylaxis, eperisone hypersensitivity

\section{From:}

${ }^{1}$ Department of Allergy and Clinical Immunology, Asan Medical Center, University of Ulsan College of Medicine, Seoul, Korea

${ }^{2}$ Department of Internal Medicine, Chungnam National University Hospital, Daejeon, 282, Munhwa-ro, Jung-gu, Daejeon, Korea

* SYY and HSK contributed equally to this work.

Corresponding author:

1. Hyouk-Soo Kwon

Department of Allergy and Clinical Immunology, Asan Medical Center, University of Ulsan College of Medicine, 88 Olympic-ro 43 gil, Songpa-gu, Seoul 05505, Korea E-mail: kwonhs21@gmail.com

2. Sun-Young Yoon

Department of Internal Medicine, Chungnam National University Hospital, Daejeon, 282, Munhwa-ro, Jung-gu, Daejeon, Korea E-mail: ggulcha2000@naver.com

\author{
Abbreviations \\ IDT intradermal test \\ OPT oral provocation test \\ ADDRESS Asan Adverse Drug Reaction Electronic Medical Record \\ Surveillance System \\ WHO-ART World Health Organization-Adverse Reaction Terminol- \\ ogy \\ WHO-UMC World Health Organization-Uppsala Monitoring Center \\ SPT skin prick tests
}

\section{Introduction}

Eperisone hydrochloride is a centrally acting muscle relaxant, which is used for the treatment of muscle spasms and pain. It is well-tolerated with minimal sedation. ${ }^{1}$ Hypersensitivity reactions to eperisone have been reported. Among the reported reactions, immediate-type hypersensitivity was the most common. ${ }^{2-7}$ Delayed-type hypersensitivity, such as acute 
generalized exanthematous pustulosis, ${ }^{8}$ fixed drug eruptions, ${ }^{9}$ and maculopapular rashes, ${ }^{10}$ have also been reported to a lesser extent. Despite the wide usage of eperisone, few studies have been conducted on the hypersensitivity reactions to eperisone.

The mechanism of drug-induced immediate-type hypersensitivity includes both immunoglobulin E (IgE)-mediated and non-IgE-mediated reactions. The oral provocation test (OPT) is the gold standard for the diagnosis of drug-induced hypersensitivity reactions, irrespective of the mechanism. However, this test may cause severe anaphylaxis and increase the risk of test-related morbidity, which raises an ethical dilemma of performing the test in selected patients with severe anaphylaxis. Skin testing is a safe and useful diagnostic tool for IgE-mediated drug allergies, despite its relatively low sensitivity. If the clinical history of a patient with severe druginduced anaphylaxis shows high causality of the suspected culprit drug, a positive skin test result may increase the certainty of determining the culprit drug without putting the patient at risk due to the OPT.

The objectives of this study were to analyze the clinical manifestations of eperisone-induced immediate-type hypersensitivity and to evaluate the role of an intradermal test (IDT) in eperisone-induced anaphylaxis.

\section{Materials and methods Subjects}

This study was based on a retrospective chart review of patients with eperisone-induced immediate-type hypersensitivity reactions. The cases of eperisone hypersensitivity were extracted from the Asan Adverse Drug Reaction Electronic Medical Record Surveillance System (ADDRESS). ${ }^{11}$ All electronic medical reports were reviewed. Clinical manifestations were reported according to World Health OrganizationAdverse Reaction Terminology (WHO-ART) and included assessments according to the World Health OrganizationUppsala Monitoring Center (WHO-UMC) causality criteria. ${ }^{12}$ Among the cases, only the patients who manifested immediate-type hypersensitivity reactions and visited the allergy clinic between January 2011 and May 2018 were enrolled. Eperisone-induced immediate-type hypersensitivity reactions that were assessed to have either certain or probable causality were selected. The severity of immediate-type hypersensitivity was classified according to the grading system of anaphylaxis by Brown et al. ${ }^{13}$ The presences of confusion, collapse, unconsciousness, or incontinence which were associated with either hypotension or hypoxia were defined as severe anaphylaxis. Features suggesting respiratory, cardiovascular, or gastrointestinal involvement such as dyspnea, stridor, wheeze, nausea, vomiting, dizziness, diaphoresis, chest or throat tightness, or abdominal pain were checked to define moderate anaphylaxis. Reactions limited only to the skin and subcutaneous tissues were defined as mild reaction. This study was approved by the institutional review board of Asan Medical Center.

\section{Intradermal tests}

IDTs were performed using a solution of eperisone hydrochloride (Exoperine 50 mg; Hanmi Pharmaceutical, Seoul,
Korea) in $0.9 \%$ saline. The external layer of sugar coating was uncoated manually, and the remaining tablet was ground to powder. It was solubilized in $5 \mathrm{~mL}$ of $0.9 \%$ saline. The solution was centrifuged at 13,000 RPM, and the supernatant solution was sterilized through a single-use syringe filter (Minisart NML Syringe Filter, $0.2 \mu \mathrm{m}$, Sartorius AG, Göttingen, Germany). To determine the non-irritating concentration, IDTs with various dilutions of eperisone solution were conducted on 10 healthy volunteers who had no exposure to eperisone. The non-irritating dose for IDT was determined as $10 \mathrm{mg} / \mathrm{mL}$.

All reagents were freshly prepared within 1 hour of testing. Skin tests were performed at least 2 weeks after the hypersensitivity reaction to minimize false-negative results. IDTs were performed on the extensor surface of the arm, with a small volume $(0.02 \mathrm{~mL})$ that produced a bleb of 2 to $3 \mathrm{~mm}$ in diameter. A histamine prick $(10 \mathrm{mg} / \mathrm{mL})$ was used as a positive control. Negative control of the IDT was performed with $0.9 \%$ saline. When read after $20 \mathrm{~min}$, IDT results were considered positive if a wheal greater than $5 \mathrm{~mm}$ in diameter was observed.

\section{Oral provocation tests}

To determine the culprit drug of anaphylaxis, OPTs were performed in some cases after obtaining informed consent. The dose of eperisone in the OPT was escalated by 4 steps every 30 minutes with the following doses: $5 \mathrm{mg}, 10 \mathrm{mg}, 10 \mathrm{mg}$, and $25 \mathrm{mg}$.

\section{Statistical analyses}

The results for the continuous variables were expressed as mean \pm standard deviation (SD). Categorical data were reported using frequencies and percentages. The Mann-Whitney U test, Fisher's exact test, Kruskal-Wallis test, and linear-by-linear association were used to assess the different subgroups. Results were considered significant when $p<0.05$. Data analysis was performed using SPSS software (version 21.0; IBM Corporation, Armonk, NY, USA).

\section{Results \\ Clinical characteristics of patients with eperisone hypersen- sitivity}

There were 81 adverse drug reaction reports related to eperisone. A total of 23 patients with immediate-type hypersensitivity reactions who showed certain or probable causality assessments were enrolled for analysis. The baseline characteristics and clinical manifestations are shown in Table $\mathbf{1 .}$ The mean age was 44.7 years (26-80 years), and $73.9 \%$ of the patients were female. Eight patients $(34.8 \%)$ had histories of allergic diseases (4, allergic rhinitis; 1 , asthma; 1, atopic dermatitis; 1, NSAIDs hypersensitivity; 1, urticaria).

Neither mortality nor permanent harm occurred. The most common manifestations were cutaneous symptoms, such as urticaria, skin rashes, pruritus, erythema, and angioedema, representing all the cases. Gastrointestinal symptoms were the second-most frequent $(65.2 \%, 15$ patients). Respiratory symptoms were manifested in 13 (56.5\%) patients. Cardiovascular symptoms were also reported in 9 patients 
Table 1. Clinical characteristics of patients with eperisone hypersensitivity

\begin{tabular}{|c|c|}
\hline Characteristics & $\mathbf{N}(\%)$ \\
\hline Number of subjects & $23(100)$ \\
\hline Mean age (years) ${ }^{\dagger}$ & $44.74 \pm 14.16$ \\
\hline Gender (M:F) & $6: 17(26.1: 73.9)$ \\
\hline Allergic disease & $8(34.8)$ \\
\hline Number of events ${ }^{\dagger}$ & $1.74 \pm 0.81$ \\
\hline \multicolumn{2}{|l|}{ Anaphylaxis severity } \\
\hline Mild/moderate/severe & $\begin{array}{c}4 / 10 / 9 \\
(17.4 / 43.5 / 39.1)\end{array}$ \\
\hline Mean onset time (minutes) ${ }^{\dagger}$ & $62.61 \pm 71.09$ \\
\hline \multicolumn{2}{|l|}{ Onset time categorized (minutes) } \\
\hline $0-15 \min$ & $2(8.7)$ \\
\hline $16-30 \mathrm{~min}$ & $10(43.5)$ \\
\hline $31-60 \mathrm{~min}$ & $7(30.4)$ \\
\hline$\geq 61 \mathrm{~min}$ & $4(17.4)$ \\
\hline \multicolumn{2}{|l|}{ WHO-UMC ${ }^{\ddagger}$ causality assessment } \\
\hline Certain/Probable & $17 / 6(73.9 / 26.1)$ \\
\hline Serum total $\operatorname{IgE}(\mathrm{kU} / \mathrm{L})^{\dagger}$ & $345.5 \pm 407.29$ \\
\hline \multicolumn{2}{|l|}{ Reported clinical manifestations } \\
\hline Cutaneous (urticaria, angioedema, rash, pruritis) & $23(100)$ \\
\hline $\begin{array}{l}\text { Gastrointestinal (nausea, vomiting, diarrhea, } \\
\text { abdominal pain, incontinence) }\end{array}$ & $15(65.2)$ \\
\hline Respiratory (dyspnea, cough, nasal congestion) & $13(56.5)$ \\
\hline $\begin{array}{l}\text { Cardiovascular (chest discomfort, hypotension, } \\
\text { palpitations, bradycardia) }\end{array}$ & $9(39.1)$ \\
\hline
\end{tabular}

${ }^{\dagger}$ Data are presented as mean \pm standard deviation.

${ }^{\ddagger}$ WHO-UMC, World Health Organization-Uppsala Monitoring Center; IgE, immunoglobulin E
(39.1\%), among whom 7 patients experienced hypotension. Hypersensitivity reactions occurred within 15 minutes in $8.7 \%$, within 30 minutes in $52.2 \%$, and within 60 minutes in $82.6 \%$ of the patients, cumulatively, after intake of eperisone.

\section{Comparison of the clinical characteristics of eperisone hyper- sensitivity according to the severity}

We compared the clinical characteristics of patients in the non-severe (mild and moderate) and the severe reaction groups (Table 2). We also compared the 3 groups (mild vs. moderate vs. severe) (Table 3).

Table 2. Comparison of the clinical characteristics of eperisone hypersensitivity according to anaphylaxis severity (non -severe vs. severe)

\begin{tabular}{|c|c|c|c|}
\hline & $\begin{array}{c}\text { Non-severe } \\
\mathbf{N}(\%)\end{array}$ & $\begin{array}{l}\text { Severe } \\
\text { N (\%) }\end{array}$ & $p$ value \\
\hline Number of subjects & $14(60.9)$ & $9(39.1)$ & \\
\hline Age (years)* & $42.07 \pm 11.53$ & $48.89 \pm 17.42$ & $0.403^{\dagger}$ \\
\hline Gender (M:F) & $4: 10(28.6: 66.7)$ & $2: 7(22.22: 77.78)$ & $1.00^{\varsigma}$ \\
\hline Number of events* & $1.79 \pm 0.70$ & $1.67 \pm 1$ & $0.516^{\dagger}$ \\
\hline \multicolumn{4}{|l|}{ Skin test } \\
\hline positive/negative & $0 / 4(0 / 100)$ & $5 / 0(100 / 0)$ & 0.008 \\
\hline $\begin{array}{l}\text { Mean onset time } \\
\text { (minutes) }^{*}\end{array}$ & $84.29 \pm 83.73$ & $28.89 \pm 20.12$ & $0.011^{\dagger}$ \\
\hline \multicolumn{4}{|c|}{ WHO-UMC causality assessment } \\
\hline Certain/Probable & $9 / 5(64.3 / 35.7)$ & $8 / 1(88.9 / 11.1)$ & $0.340^{5}$ \\
\hline \multicolumn{4}{|c|}{ Clinical manifestations } \\
\hline Cutaneous & $14(100)$ & $9(100)$ & $1.00^{\varsigma}$ \\
\hline Respiratory & $6(60)$ & $7(77.78)$ & $0.197^{\S}$ \\
\hline Gastrointestinal & $9(90)$ & $7(77.78)$ & $0.657^{\S}$ \\
\hline Cardiovascular & $2(20)$ & $7(77.78)$ & $0.007^{\S}$ \\
\hline
\end{tabular}

* Data are presented as mean \pm standard deviation

${ }^{\dagger}$ non-severe vs. severe, Mann-Whitney U test

${ }^{\S}$ non-severe vs. severe, Fisher's exact test

NA; not available

Table 3. Comparison of the clinical characteristics of eperisone hypersensitivity according to anaphylaxis severity (between 3 groups, mild vs. moderate vs. severe)

\begin{tabular}{|c|c|c|c|c|}
\hline & $\begin{array}{l}\text { Mild } \\
\text { N (\%) }\end{array}$ & $\begin{array}{c}\text { Moderate } \\
\text { N (\%) }\end{array}$ & $\begin{array}{l}\text { Severe } \\
\mathbf{N}(\%)\end{array}$ & $p$ value \\
\hline Number of subjects & $4(17.39)$ & $10(43.49)$ & $9(39.13)$ & \\
\hline Age (years)* & $31.25 \pm 5.12$ & $46.40 \pm 10.51$ & $48.89 \pm 17.42$ & $0.075^{\dagger}$ \\
\hline Gender (M:F) & $0: 4(0: 100)$ & $4: 6(40: 60)$ & $2: 7(22.22: 77.78)$ & $0.653^{\varsigma}$ \\
\hline Number of events* & $1.50 \pm 1.00$ & $1.90 \pm 0.57$ & $1.67 \pm 1$ & $0.342^{\dagger}$ \\
\hline \multicolumn{5}{|l|}{ Skin test } \\
\hline positive/negative & $0 / 0$ & $0 / 4(0 / 100)$ & $5 / 0(100 / 0)$ & 0.008 \\
\hline Mean onset time (minutes)* & $75.00 \pm 30.00$ & $88.00 \pm 98.86$ & $28.89 \pm 20.12$ & $0.022^{\dagger}$ \\
\hline
\end{tabular}


Table 3. (Continued)

\begin{tabular}{|c|c|c|c|c|}
\hline & $\begin{array}{l}\text { Mild } \\
\text { N (\%) }\end{array}$ & $\begin{array}{c}\text { Moderate } \\
\text { N (\%) }\end{array}$ & $\begin{array}{l}\text { Severe } \\
\text { N (\%) }\end{array}$ & $p$ value \\
\hline \multicolumn{5}{|c|}{ WHO-UMC causality assessment } \\
\hline Certain/Probable & $3 / 1(75 / 25)$ & $6 / 4(60 / 40)$ & $8 / 1(88.9 / 11.1)$ & $0.400^{9}$ \\
\hline \multicolumn{5}{|c|}{ Clinical manifestations } \\
\hline Cutaneous & $4(100)$ & $10(100)$ & $9(100)$ & $0.763^{9}$ \\
\hline Respiratory & NA & $6(60)$ & $7(77.78)$ & $0.197^{\S}$ \\
\hline Gastrointestinal & NA & $9(90)$ & $7(77.78)$ & $0.657^{\S}$ \\
\hline Cardiovascular & NA & $2(20)$ & $7(77.78)$ & $0.007^{\varsigma}$ \\
\hline
\end{tabular}

* Data are presented as mean \pm standard deviation

${ }^{\dagger}$ mild vs. moderate vs. severe, Kruskal-Wallis test

${ }^{5}$ moderate vs. severe, Fisher's exact test

' mild vs. moderate vs. severe, linear-by-linear association

NA; not available

IDTs using the eperisone solution were performed in 9 patients with suspected eperisone-induced hypersensitivity. The mean sizes of positive reactions were $7.2 \pm 2.0 \mathrm{~mm}$ for wheals and $15.8 \pm 4.6 \mathrm{~mm}$ for flares. The sensitivity rate was $55.55 \%$. Five patients among the severe anaphylaxis group were evaluated with IDT, and all showed positive results. All of the four patients among the moderate anaphylaxis group who have done IDT showed negative results (Figure 1). There was a significantly positive relationship between the IDT results and severity ( $p=0.008$, between the 2 groups). In patients with severe anaphylaxis, there were significantly shorter onset times compared to those with moderate anaphylaxis $(28.89 \pm$ 20.12 vs. $88.00 \pm 98.86 \mathrm{~min}, p=0.011$ ).

Fourteen out of twenty-three patients agreed to undergo OPTs (Table 4). All patients experienced acute onset of immediate-type hypersensitivity reactions (urticaria, angioedema,

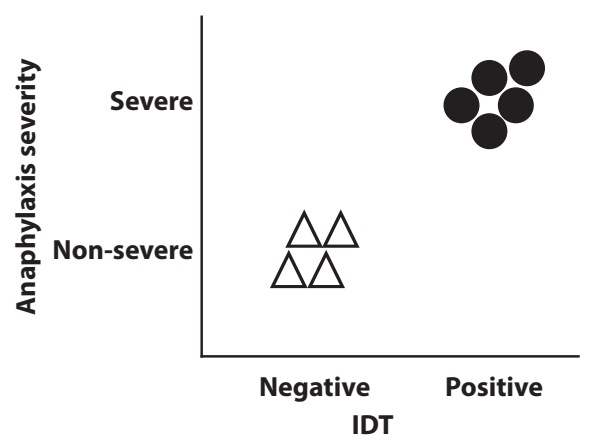

Figure 1.

skin rashes, or hypotension), and these patients were confirmed with eperissone-induced immediate-type hypersensitivity.

Table 4. Individual results of IDTs, OPTs, and anaphylaxis severity

\begin{tabular}{|c|c|c|c|c|c|c|c|}
\hline No. & $\begin{array}{l}\text { Age } \\
\text { (years) }\end{array}$ & Sex & $\begin{array}{c}\text { IDT } \\
\text { (wheal/flare) }\end{array}$ & OPT & $\begin{array}{l}\text { Onset } \\
(\mathrm{min})\end{array}$ & Clinical manifestations & Severity \\
\hline 1 & 43 & $\mathrm{~F}$ & - & + & 30 & urticaria, erythema, dizziness, abdominal pain & Moderate \\
\hline 2 & 42 & M & - & + & 30 & urticaria, angioedema, dizziness, diaphoresis, dyspnea, chest tightness & Moderate \\
\hline 3 & 58 & M & - & + & 30 & urticaria, dizziness, cough, palpitation, vomiting, abdominal pain & Moderate \\
\hline 4 & 28 & $\mathrm{~F}$ & - & + & 40 & urticaria, angioedema, dyspnea, vomiting, abdominal pain & Moderate \\
\hline 5 & 47 & $\mathrm{~F}$ & $+(11 / 20)$ & ND & 20 & $\begin{array}{l}\text { urticaria, hypotension, dizziness, diaphoresis, collapse, vomiting, abdominal } \\
\text { pain }\end{array}$ & Severe \\
\hline 6 & 64 & $\mathrm{~F}$ & $+(7 / 15)$ & ND & 30 & urticaria, angioedema, hypotension, throat tightness, dyspnea & Severe \\
\hline 7 & 56 & $\mathrm{~F}$ & $+(6 / 12)$ & + & 60 & $\begin{array}{l}\text { urticaria, angioedema, hypotension, hypoxia, dyspnea, vomiting, abdominal } \\
\text { pain }\end{array}$ & Severe \\
\hline 8 & 43 & F & $+(5 / 10)$ & + & 5 & urticaria, angioedema, hypotension, dizziness, dyspnea, abdominal pain & Severe \\
\hline 9 & 59 & M & $+(7 / 22)$ & ND & 5 & $\begin{array}{l}\text { urticaria, erythema, hypotension, hypoxia, collapse, incontinence, dizziness, } \\
\text { dyspnea }\end{array}$ & Severe \\
\hline 10 & 28 & $\mathrm{~F}$ & ND & + & 60 & urticaria, pruritus & Mild \\
\hline
\end{tabular}


Table 4. (Continued)

\begin{tabular}{|c|c|c|c|c|c|c|c|}
\hline No. & $\begin{array}{c}\text { Age } \\
\text { (years) }\end{array}$ & Sex & $\begin{array}{c}\text { IDT } \\
\text { (wheal/flare) }\end{array}$ & OPT & $\begin{array}{l}\text { Onset } \\
(\mathrm{min})\end{array}$ & Clinical manifestations & Severity \\
\hline 11 & 34 & $\mathrm{~F}$ & ND & + & 60 & urticaria, pruritus, angioedema & Mild \\
\hline 12 & 26 & $\mathrm{~F}$ & ND & + & 120 & urticaria, pruritus, angioedema & Mild \\
\hline 13 & 37 & $\mathrm{~F}$ & ND & ND & 60 & urticaria, pruritus, erythema & Mild \\
\hline 14 & 60 & $\mathrm{~F}$ & ND & + & 30 & conjunctival injection, pruritus, dyspnea, vomiting & Moderate \\
\hline 15 & 48 & $\mathrm{~F}$ & ND & + & 300 & urticaria, pruritus, dyspnea, abdominal pain & Moderate \\
\hline 16 & 59 & $\mathrm{~F}$ & ND & ND & 90 & urticaria, pruritus, dizziness, vomiting & Moderate \\
\hline 17 & 41 & $\mathrm{~F}$ & ND & ND & 60 & dyspnea, vomiting, diarrhea & Moderate \\
\hline 18 & 36 & M & ND & ND & 240 & urticaria, vomiting & Moderate \\
\hline 19 & 49 & M & ND & ND & 30 & urticaria, angioedema, dyspnea & Moderate \\
\hline 20 & 28 & $\mathrm{~F}$ & ND & + & 60 & $\begin{array}{l}\text { urticaria, angioedema, hypotension, collapse, dizziness, dyspnea, nausea, vomit- } \\
\text { ing, abdominal pain, diarrhea }\end{array}$ & Severe \\
\hline 21 & 32 & $\mathrm{~F}$ & ND & + & 30 & $\begin{array}{l}\text { urticaria, angioedema, hypotension, unconsciousness, dizziness, dyspnea, } \\
\text { abdominal pain }\end{array}$ & Severe \\
\hline 22 & 31 & $\mathrm{~F}$ & ND & + & 20 & urticaria, angioedema, dizziness, abdominal pain, incontinence, diarrhea & Severe \\
\hline 23 & 80 & M & ND & ND & 30 & urticaria, hypotension, hypoxia, dizziness, dyspnea & Severe \\
\hline
\end{tabular}

F, female; M, male; IDT, intradermal test; OPT, oral provocation test; ND, not done

\section{Discussion}

Eperisone is a commonly prescribed oral muscle relaxant. ${ }^{14}$ It acts centrally by relaxing skeletal and vascular smooth muscles to improve circulation and suppress pain reflexes. In this study, the medical records of patients with immediate-type hypersensitivity to eperisone were systematically reviewed using the single-center pharmacovigilance data and electronic medical record. This study revealed comprehensive data regarding eperisone hypersensitivity reactions, including clinical manifestations, IDT results, and OPT results. We showed that IDTs were more likely to be positive in severe anaphylaxis than non-severe anaphylaxis. Also, the onset time of severe anaphylaxis was significantly shorter than that of the non-severe reaction.

Several case reports of eperisone-induced hypersensitivity have been published, most of which were of immediate-type hypersensitivity reactions. One case showed erythema and edema, and an OPT showed that eperisone was the culprit drug. ${ }^{2}$ Two cases were confirmed by using OPTs. Skin prick tests (SPTs) and IDTs with eperisone were performed to show negative results. ${ }^{3}$ One case of eperisone-induced anaphylaxis was confirmed after a positive OPT result, but SPT and basophil activation test results were negative. ${ }^{4}$ In one case of eperisone-induced severe anaphylaxis who presented with hypotension and hypoxia, IDT with eperisone showed a positive result. ${ }^{5}$ In a case series, there were 3 cases of eperisone-induced immediate-type hypersensitivity confirmed by OPTs, but IDTs urticaria and were not performed. Among the 3 cases, 2 patients experienced dyspnea, and one patient experienced urticaria and hypotension. ${ }^{6}$ In another study, IDTs for eperisone were performed in 2 patients, and one of them, who presented with moderate anaphylaxis, showed a positive response to the IDT. ${ }^{7}$ To summarize, IDTs with eperisone were done in a few cases reports, ${ }^{3,5,7}$ and only 2 cases $^{5,7}$ showed positive results among which one positive result was shown in severe anaphylaxis patient. Our study included nine IDT results, which is small but yet the largest to include in a single study.

In real-world practice, it is the severe anaphylaxis patients who need safe diagnostic tools such as skin tests other than the risky OPTs to avoid test-related complications. IDTs are relatively safe and may be utilized to determine the culprit drug of hypersensitivity reactions in patients who manifest with severe anaphylaxis. In our study, no patient experienced anaphylaxis during the IDTs, confirming its known safety. There was a significantly positive relationship between anaphylaxis severity and positive IDT results $(p=0.008)$. This suggests that IDTs with eperisone are more useful in patients with severe anaphylaxis. However, the number of tested patients was small and larger study is needed to confirm our observation.

In severe anaphylaxis, IgE-related reactions are likely to be important. However, in moderate anaphylaxis, despite the number of patients being small, none exhibited a positive IDT result.

There are several possible explanations for eperisone-induced acute hypersensitivity reactions with negative IDT results. First, because eperisone transforms into several metabolites in vivo, it could be the metabolites and not the original eperisone molecule that induces IgE-mediated reactions. Second, because eperisone has vasodilating effects, ${ }^{15}$ anaphylactoid reactions might occur as a result of vasodilation due to eperisone. Lastly, eperisone could have a direct effect on 
mast cells to induce pseudoallergic (IgE-independent) release of histamine via MRGPRX2 receptor, ${ }^{16}$ although more research is required to clarify this hypothesis. Delayed onset time of the moderate anaphylaxis reactions could be the result of more time-consuming metabolism or other biochemical mechanisms mentioned above compared to immediate interaction between the drug and IgE in severe anaphylaxis. Nonetheless, positive IDT results in severe anaphylaxis patients suggest an involvement of IgE-mediated immune reaction against eperisone.

The IDT results of our study are reliable. IDTs using eperisone solution were well established to minimize false positive results by testing the non-irritating concentrations in 10 volunteers. All patients who underwent IDTs were confirmed to have positive results after the OPTs. Despite the known vasodilating effects of eperisone, ${ }^{15}$ we could not observe any vasodilating effect visually on the tested skin of the 10 healthy volunteers as well as the 4 moderate anaphylaxis patients. The findings of our study show that the diagnosis of eperisone-induced severe anaphylaxis could be strongly supported by the positive results of IDTs in selected patients. OPTs may be dangerous for patients with severe anaphylaxis and could cause ethical issues. Thus, in this subgroup, wherein that could be a problem, the IDT with eperisone solution could be a crucial test which can be easily conducted.

SPT is much easier to perform and safer than IDT. However, there are limitations with SPT when performing with chemicals. Unlike protein allergens, the value of SPTs with the chemical drugs are limited by low-potency extracts and may give false-negative results. The concentration of allergen extract required to elicit a positive reaction with IDT may be 1000-30000 times smaller than that necessary for a positive SPT. When we performed skin prick test preliminarily, all results were negative. Thus, we used IDT to confirm eperisone hypersensitivity, which gave us the results presented. Sterilizing extract used to be a difficult process in the past. However, with the commercialized affordable syringe filters, sterilization has become a simple process. Compared to conventional preparation methods of drug solutions for IDT, sterilization requires only one more step of syringe filtration. Considering the medical cost for the repeated anaphylaxis due to the uncertain diagnosis of drug allergy, using the IDT with the sterilized drug solution could be a cost-effective method.

Eperisone is commonly prescribed with NSAIDs to relieve muscular pain. Eperisone is not usually suspected as the primary candidate of anaphylaxis since it is more often prescribed with NSAIDS. Physicians might jump to the conclusion that the culprit drug is an NSAID since they are the most common culprit drug of anaphylaxis. ${ }^{17}$ However, all physicians should remain aware that eperisone could cause drug-induced anaphylactic reactions and that IDTs or OPTs should be done to find the culprit drug.

There are limitations to this study. It is based on self-reported ADRs and is retrospective in design. The number of patients was relatively small, and a limited number of patients agreed to participate in the IDTs and OPTs. We did not perform IDTs and OPTs using pure eperisone chemical. Oral tablets are formed with many additives other than the active chemical and hypersensitivity to those additives have not been ruled-out completely. However, the patients have not shown hypersensitivity reactions to other oral tablets which commonly shares similar ingredients. A further prospective study with IDT and OPT done in every enrolled patient could give us more concrete information of the utility of IDT in eperisone-induced hypersensitivity reactions.

In conclusion, we reviewed the clinical manifestations of eperisone-induced immediate-type hypersensitivity with the largest number of patients to date. In severe anaphylaxis cases, there were shorter onset times and higher positive IDT results compared to non-severe reactions. The IDT could be a safe and useful diagnostic tool, especially for eperisoneinduced severe anaphylaxis.

\section{Acknowledgement}

This study was supported by a grant (2015-584) from the Asan Institute for Life Sciences, Asan Medical Center, Seoul, Korea.

\section{Conflict of interest}

The authors have no conflict of interest to declare.

\section{Funding \\ None}

\section{Authors' contributions}

BS performed the final analyses, draughted the initial manuscript, and reviewed and revised the manuscript. HSK conceptualized and designed the study, reviewed and revised the manuscript. SYY reviewed and revised the manuscript, substantially critically revised the article for important intellectual content. All authors have read and approved the final form of the manuscript. WJS, TBK, YSC, and HBM designed the study, coordinated and supervised data collection. JHL, HKW, JA, and YK performed the statistical analyses and interpretation of the results.

\section{References}

1. Bresolin N, Zucca C, Pecori A. Efficacy and tolerability of eperisone in patients with spastic palsy: a cross-over, placebo-controlled dose-ranging trial. Eur Rev Med Pharmacol Sci. 2009;13:365-70.

2. Ueno T, Kawana S. [A case of eperisone hydrochloride (myonal)--induced drug eruption leading to erythema and angioedema]. Arerugi. 2007;56: 709-13. Japanese.

3. Hur GY, Hwang EK, Moon JY, Ye YM, Shim JJ, Park HS, et al. Oral muscle relaxant may induce immediate allergic reactions. Yonsei Med J. 2012;53:863-5.

4. Miki Y, Washio K, Masaki T, Nakata K, Fukunaga A, Nishigori C. A case of eperisone hydrochloride-induced anaphylaxis: A true type I reaction? Allergol Int. 2017;66:152-3.

5. Kim SH, Lee J, Kim SH, Kim HW, Kim YU, Lim Y, et al. Anaphylaxis caused by muscle relaxant (eperisone hydrochloride). Allergy Asthma Respir Dis. 2013;1:172-5. Korean.

6. Kang DY, Lee J, Sohn K-H, Kang SY, Cho YS, Kang H-R. A case series of eperisone-induced immediate hypersensitivity. Allergy Asthma Respir Dis. 2017;5:228-31. Korean.

7. Kim SY, Kim JH, Jang YS, Choi JH, Park S, Hwang YI, et al. The Basophil Activation Test Is Safe and Useful for Confirming Drug-Induced Anaphylaxis. Allergy Asthma Immunol Res. 2016;8:541-4.

8. Yamamoto Y, Kadota M, Nishimura Y. A case of eperisone hydrochloride -induced acute generalized exanthematous pustulosis. J Dermatol. 2004;31:769-70. 
9. Choonhakarn C. Non-pigmenting fixed drug eruption: a new case due to eperisone hydrochloride. Br J Dermatol. 2001;144:1288-9.

10. Balaraddiyavar N, Bhushan A, Kotinatot BC, Huggi G. Eperisone hydrochloride-induced maculopapular rash. Indian J Pharmacol. 2016; 48:604-5.

11. Park CS, Kim TB, Kim SL, Kim JY, Yang KA, Bae YJ, et al. The use of an electronic medical record system for mandatory reporting of drug hypersensitivity reactions has been shown to improve the management of patients in the university hospital in Korea. Pharmacoepidemiol Drug Saf. 2008;17:919-25.

12. Karch FE, Lasagna L. Adverse drug reactions. A critical review. JAMA. $1975 ; 234: 1236-41$
13. Brown SG. Clinical features and severity grading of anaphylaxis. J Allergy Clin Immunol. 2004;114:371-6.

14. Matsunaga M, Uemura Y, Yonemoto Y, Kanai K, Etoh H, Tanaka S, et al. Long-lasting muscle relaxant activity of eperisone hydrochloride after percutaneous administration in rats. Jpn J Pharmacol. 1997;73:215-20.

15. Fujioka $M$, Kuriyama $H$. Eperisone, an antispastic agent, possesses vasodilating actions on the guinea-pig basilar artery. J Pharmacol Exp Ther. 1985;235:757-63.

16. McNeil BD, Pundir P, Meeker S, Han L, Undem BJ, Kulka M, et al Identification of a mast-cell-specific receptor crucial for pseudo-allergic drug reactions. Nature. 2015;519:237-41.

17. Webb LM, Lieberman P. Anaphylaxis: a review of 601 cases. Ann Allergy Asthma Immunol. 2006;97:39-43. 